\title{
Estimates of Fog Element Length
}

\author{
David H. George \\ National Weather Service, NOA A, Slerling, Va. 22170
}

2 February 1972 and 24 April 1972

\begin{abstract}
The size of horizontal transmittance discontinuities must be known in order to optimize time and spatial representativeness of automated transmittance measurements.

Results of computations using observed parameters are presented in a table of fog element sizes. Most fog elements embedded in a larger fog volume ranged in size from about 50 to $100 \mathrm{ft}$ in length. This information is useful to researchers interested in time and spatial representativeness of atmospheric transmittance data.
\end{abstract}

\section{Introduction}

Several investigators have noticed the lack of time and spatial representativeness of atmospheric transmittance measurements. A 1958 Air Force study (Morton and Haig) concluded "that the information obtained from those . . . instruments (transmissometers) applies only to the location of the sensing elements and is true only at the actual time of measurement." In that study, the transmittance measuring instruments were $4000 \mathrm{ft}$ apart. Later studies by Lefkowitz (1962) and by Schlatter and Lefkowitz (1968) produced similar results using transmissometers placed along an airport runway. The National Bureau of Standards (1970) is presently analyzing two years of transmissometer records from three instruments placed at 5,10 and 15 $\mathrm{ft}$ above ground level. Initial analysis shows no simple, direct relationship between height and atmospheric transmittance.
Much of the inconclusiveness of those studies resulted from the use of arbitrary transmissometer configurations and arbitrary data averaging times. That is, the studies were not able to use instrument configurations or observing times which could maximize time and spatial data representativeness. The fact is, optimized observing schemes are still not available for atmospheric transmittance measurements.

The problems of time and spatial representativeness over a finite area can be partially solved by increasing the number of sensors and/or increasing the averaging time of measurement up to some optimum value since both the optimum number of sensors and the optimum measuring time are affected by the horizontal variability of what I have chosen to call fog elements. By fog elements, I mean those more dense, cloud-like discontinuities which sometimes appear to roll or to translate horizontally in sheets through a larger fog volume. Fog elements, then, are the micro-fog volumes 
embedded in a meso-fog volume. Aircraft pilots sometimes refer to fog elements as noodles in the soup.

This note is addressed to fog variability as it applies to automated, instrument-derived transmittance measurements. It has little relationship to algorithms such as Koschmieder's and Allard's laws which are frequently used to convert atmospheric transmittance to some measure of the human observed prevailing visibility common to surface aviation and synoptic weather observations.

\section{Fog element observations}

I was fortunate to encounter nearly ideal conditions for observing and measuring the length of some fog elements embedded in a meso-scale fog volume. A fairly dense and extensive fog formed during the early morning of 29 October 1971, in the Washington, D. C., area. Light northerly winds over the area produced an upslope flow which, together with a thick cloud cover, maintained the fog until nearly mid-day. Surface winds observed at the National Weather Service Sterling Research and Development Center, located near Washington, D. C., were fairly steady, generally from the north to north-northeast at $1-5 \mathrm{kt}$. There were occasional brief direction excursions to the northnorthwest and the northeast.

The observed prevailing visibility at the Center was less than $\frac{1}{8}$ mi until nearly 0930 EST when it increased to about $\frac{1}{2} \mathrm{mi}$. Through the next $20 \mathrm{~min}$, prevailing visibility increased to over $1 \frac{1}{2} \mathrm{mi}$ as the fog continued to dissipate.

Two of the transmissometers at the Sterling Research and Development Center are oriented along northsouth measuring paths (Fig. 1). Both instruments, a $250-\mathrm{ft}$ baseline transmissometer and a 125 -ft baseline transmissometer, are sited about $6 \mathrm{ft}$ above ground level. The parallel measuring paths are $12 \mathrm{ft}$ apart. Continuous atmospheric transmittance measurements are displayed on identical strip chart recorders. Short transmissometer response times combined with low wind speeds gave the effect of nearly instantaneous recordings of transmittance changes.

With fog elements advected from the north along the measuring path, the $250-\mathrm{ft}$ baseline instrument re-

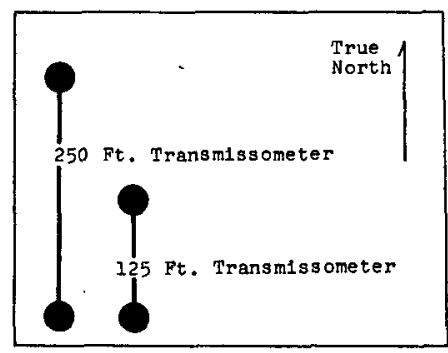

Fig. 1. The Sterling Research and Development Center transmissometer field site. Winds from the north at $1-5 \mathrm{kt}$ advected fog elements along the transmissometer measuring paths on 29 October 1971.

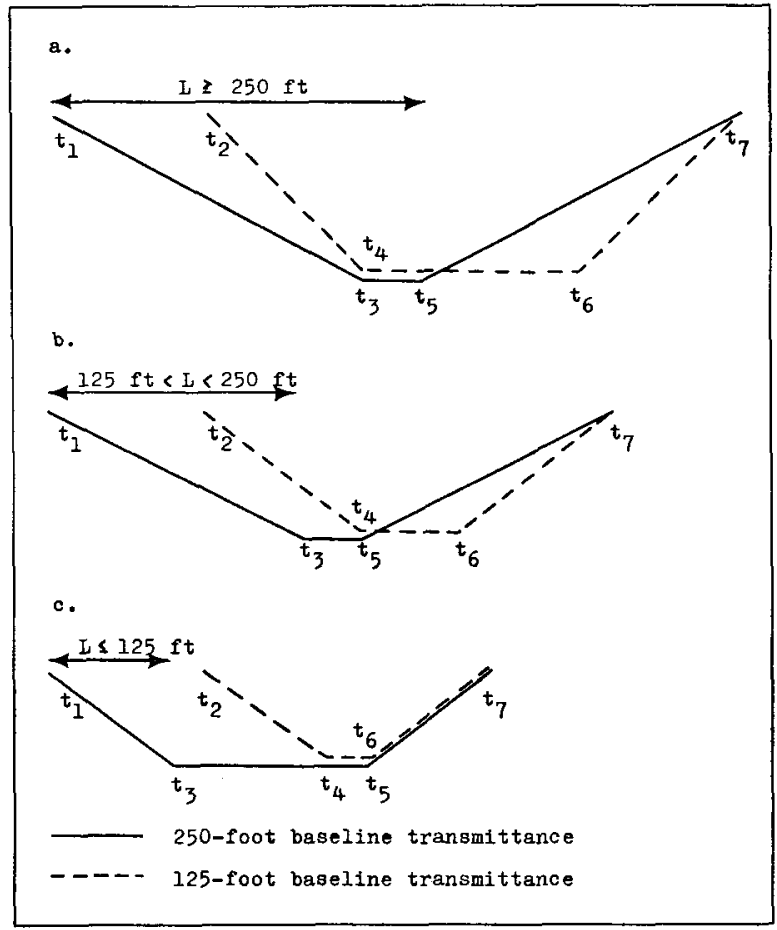

FIG. 2. Time series of atmospheric transmittance show the effect of fog element length $L$ on the shape of transmittance recordings.

sponded to changes in atmospheric transmittance before the 125-ft unit. Fig. 2a shows a time series of simplified transmittance recordings as a fog element of size $L \geqslant 250 \mathrm{ft}$ passes along the 250 - and 125 -ft measuring paths. At time $t_{1}$, the fog element leading edge passes into the $250-\mathrm{ft}$ measuring path. The $250-\mathrm{ft}$ transmittance decreases and continues to decrease until the measuring path is completely within the element at time $t_{3}$. At $t_{3}$ the trailing edge of the element enters the $250 \mathrm{-ft}$ measuring path. Multiplying the time interval $t_{5}-t_{1}$ by the north wind speed $V$ yields the fog element length $L$.

When $L<250 \mathrm{ft}$ (Fig. 2b) $t_{3}$ will be the time at which the trailing edge of the element enters the measuring path. During the time $t_{5}-t_{3}$ the entire element will be within the measuring path. The fog trailing edge leaves the measuring path at time $t_{7}$. The density of the elements is not always the same so that an element with size $L<250 \mathrm{ft}$ could produce a trace (Fig. 2b) indistinguishable from that of a less dense element of size $L \geqslant 250 \mathrm{ft}$ (Fig. 2a). The case $L=250$ (i.e., $t_{3}=t_{5}$ ) may be included with the group of $L \geqslant 250$. Although the trace would have a unique $V$-shape it would only provide a frequency of occurrence of size element exactly $250 \mathrm{ft}$ long. The sub-case $L \leqslant 125$ of the case $L<250$ is the only situation where $t_{5}-t_{3}>t_{6}-t_{4}$. Using the observed wind direction and speed, I computed the north wind vector $V$ which was moving fog elements along the transmittance measuring paths. By 


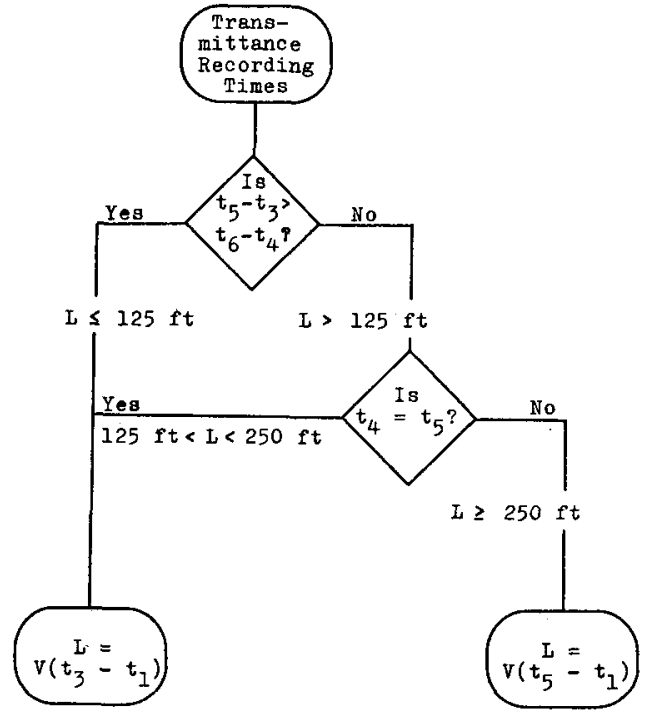

Fig. 3. The scheme for computing fog element length $L$ from observed transmittance recording times $t$ as shown in Fig. 2.

noting the time durations of transmittance decreases and increases, and by multiplying these durations by the north wind speed, I arrived at a measure of fog element length using the scheme outlined in Fig. 3 and limited by

$$
\begin{array}{ll}
L=V\left(t_{5}-t_{1}\right), & \text { for } \quad L \geqslant 250, \\
L=V\left(t_{3}-t_{1}\right), & \text { for } \quad L<250 .
\end{array}
$$

\section{Results and conclusions}

The 29 October 1971 observations indicated that all fog element lengths were less than $250 \mathrm{ft}$. The time

Table 1. Fog element lengths ( $\mathrm{ft}$ ) computed from observed transmissometer response and wind speeds.

\begin{tabular}{cccc}
\hline \hline $\begin{array}{c}\text { Wind } \\
\text { speed } \\
(\mathrm{kt})\end{array}$ & \multicolumn{3}{c}{$\begin{array}{c}t_{3}-t_{1} \text { responses } \\
\text { (sec) }\end{array}$} \\
\hline 2 & 10 & 15 & 20 \\
3 & 34 & 51 & 68 \\
4 & 51 & 76 & 102 \\
5 & 68 & 102 & 136 \\
& 85 & 127 & 170 \\
\hline
\end{tabular}

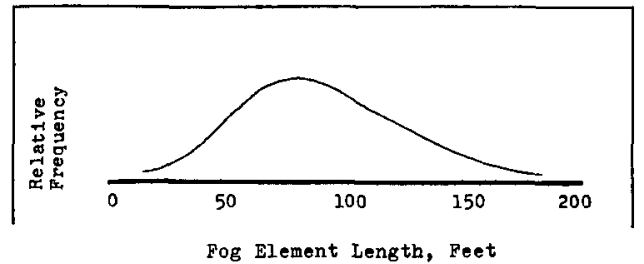

FIG. 4. Fog element length distribution postulated from 29 October 1971 observations.

intervals $t_{3}-t_{1}$ were frequently near $15 \mathrm{sec}$ although times as short as $10 \mathrm{sec}$ and as long as $20 \mathrm{sec}$ were noted. North wind speeds of $3 \mathrm{kt}$ were most common. Table 1 presents the results of computations using observed lag times and wind speeds, The matrix gives fog element sizes as observed on 29 October 1971.

I don't propose that these fog elements are representative of all fog conditions. But they do seem to be representative of the conditions encountered on 29 October at the Sterling Research and Development Center. Based on my experience, I believe that the distribution of fog element sizes embedded in the larger fog field is adequately described by the relative frequency curve in Fig. 4 . I believe that this information will be useful to others, who like myself, are attempting to model low visibility conditions and to those who must design optimum instrument configurations for automated transmittance measuring devices.

\section{REFERENCES}

Lefkowitz, Matthew, 1962: Studies in the field of approach visibility instrumentation. Federal Aviation Administration Final Report, Project No. 202-2-1X, U. S. Weather Bureau, Washington, D. C., 137 pp.

Morton, W. C., and T. O. Haig, 1958: Variations of atmospheric transmissivity and cloud height at Newark. U. S. Air Force Surveys in Geophysics No. 91, Air Force Cambridge Research Laboratories, Bedford, Mass., 32. pp.

National Bureau of Standards, 1970: Development, testing and evaluation of visual landing aids: Consolidated progress report for Jan. 1 to March 31, 1970. Washington, D. C., 12 pp.

Schlatter, E., and Matthew Lefkowitz, 1968: Evaluation of multitransmissometer systems. Federal Aviation Administration Final Report RD-68-49, ESSA-Weather Bureau, Washington, D. C., $197 \mathrm{pp}$. 